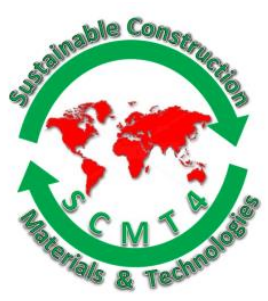

SCMT4

Las Vegas, USA, August 7-11, 2016

\title{
Experimental Investigation of Double-Lap Bonded-and-Bolted Splice Joints of Pultruded Hybrid FRP I-Beams
}

\author{
Hai Nguyen ${ }^{1 a}$, Hiroshi Mutsuyoshi ${ }^{2 a}$, Wael Zatar ${ }^{1 b}$, and Tatsuya Ishihama ${ }^{2 b}$ \\ ${ }^{1}$ Marshall University, Nick J. Rahall II Appalachian Transportation Institute, $16763^{\text {rd }}$ Avenue, \\ Huntington,WV 25755,USA, ${ }^{1 a}$ Email:<hai.nguyen.2004@gmail.com>, ${ }^{l b}$ Email: $\langle$ zatar@marshall.edu〉. \\ ${ }^{2}$ Saitama University, Department of Civil and Environmental Engineering, Shimo-Okubo 255, Sakura-ku, \\ Saitama-shi, 338-8570, Japan, ${ }^{2 a}$ Email: <mutuyosi@mail.saitama-u.ac.jp>, \\ ${ }^{2 b}$ Email: <ishihama@mtr.civil.saitama-u.ac.jp>.
}

\begin{abstract}
This work investigates the double-lap joints of FRP/steel splice plates bonded and bolted to flanges and web of pultruded hybrid CFRP/GFRP I-beams. Eight large-scale specimens with bonded-and-bolted splice joints and two control beams were tested under four-point static flexural loading. The test results indicated that the double-lap splice joints, which incorporated high-corrosion-resistant steel bolts, epoxy adhesive, and grit-blasted-surface-finish FRP splice plates, provided an effective solution for joining the hybrid FRP (HFRP) I-beams. The grit-blasted surface finish of the FRP splice plates and the epoxy adhesive contributed to improving the joint stiffness and strength. Prior to debonding, the stiffness of the bonded-and-bolted splice joints was dependent mainly upon the strength of the epoxy adhesive and the bonding surface of the splice plates, while the ultimate load and failure mode of the joints were governed by the number and strength of bolts. The specimens with failures in the splice connections showed more ductile behavior than those with failures beyond the connections, attributed to the slippage of the splice connections.
\end{abstract}

\section{INTRODUCTION}

In recent years, Fiber Reinforced Polymer (FRP) materials have been increasingly used for infrastructure applications such as bridge and building structures. FRP offers many advantages over traditional construction materials including high strength-to-weight ratio, light weight, and corrosion resistance. A hybrid FRP (HFRP) I-beam consisting of carbon fiber reinforced polymer (CFRP) and glass fiber reinforced polymer (GFRP) laminae was developed for bridge applications [Hai et al. 2010; Nguyen et al. 2013, 2014]. The HFRP I-beam was optimally designed for a four-point flexural loading using CFRP and GFRP in a beam section with a specific flange-to-web-width ratio. The HFRP I-beams were successfully applied to a pedestrian bridge construction in Kure city, Hiroshima prefecture, Japan in 2011 (figure 1). This bridge was built to replace a deteriorated steel bridge (on the right hand side of figure 1a). The bridge consists of two HFRP I-beams topped with a GFRP gratings bridge deck. It is simply supported 
with a total length of $12 \mathrm{~m}$ and an effective width of $0.75 \mathrm{~m}$. Further details of this bridge have been presented by the authors elsewhere [Nguyen et al. 2015].

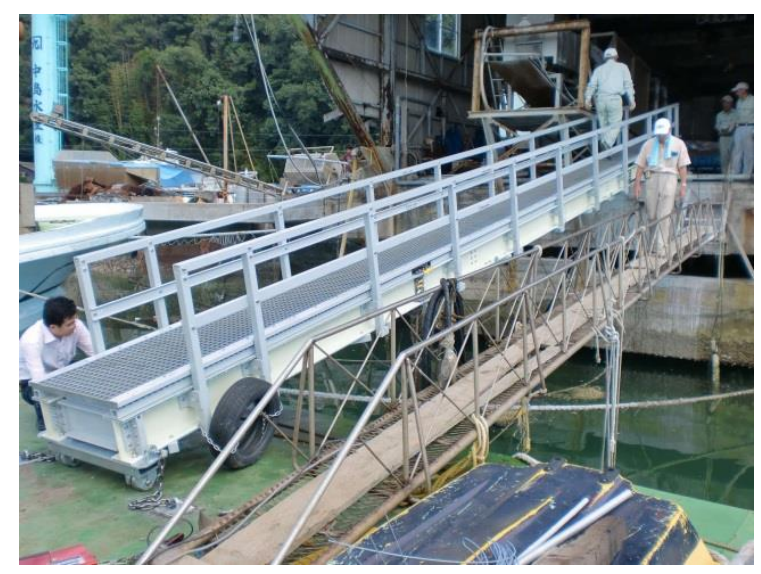

(a)

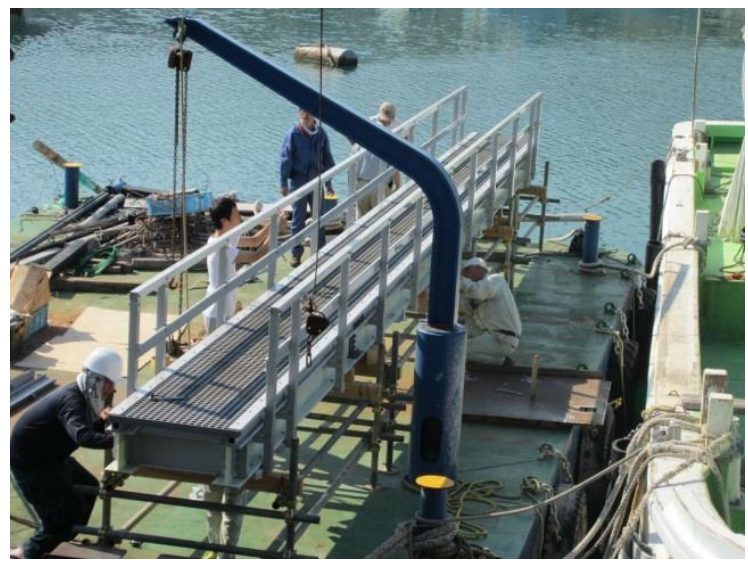

(b)

\section{Figure 1. First HFRP pedestrian bridge using HFRP I-beams in Kure, Hiroshima, Japan (2011): (a) Bridge overview; and (b) Erection of the HFRP bridge}

Over the past three decades, a large amount of research has been conducted to characterize the behavior of FRP materials. However, understanding of FRP structural joints and connections is still limited. Joints are unavoidable in all large FRP structures due to transportation and assembly requirements. FRP laminates are commonly joined by adhesive bonding, mechanical fastening, or a combination thereof. The combination is often employed as a safeguard against defects within the adhesive layer, which may lead to premature or catastrophic failure [Kelly 2006]. Numerous experimental and analytical investigations on joining of FRP laminates have been reported, especially for aerospace applications [Nelson et al. 1983; Hart-Smith 1985; Camanho and Matthews 1997; Hart-Smith 2002]. Nevertheless, limited published works with respect to splice joints of FRP beams are available in the field of civil infrastructure applications [Hai and Mutsuyoshi 2012; Turvey and Xavier 2015; Mutsuyoshi et al. 2016]. To fill in the knowledge gap, this study focuses on the experimentally determined flexural behavior of double-lap joints of FRP/steel splice plates bonded and bolted to the flanges and web of the HFRP I-beams. Eight large-scale specimens with bonded-and-bolted splice joints in flexural and shear spans and two control 
beams without joints were tested under four-point static flexural loading. Load versus deflection relationships and failure modes of all specimens are discussed.

\section{LARGE-SCALE FLEXURAL TESTING OF HFRP I-BEAM WITH BONDED-AND- BOLTED DOUBLE-LAP SPLICE JOINTS}

Test Variables. Laboratory tests were conducted on ten large-scale HFRP I-beams. The nominal dimensions of all HFRP beams were $b \times H \times t_{f} \times t_{w}=95 \times 250 \times 14 \times 9 \mathrm{~mm}$, where $b=$ flange width; $H=$ overall height of beams; $t_{f}=$ flange thickness; and $t_{w}=$ web thickness. These I-beams were fabricated by pultrusion process with a length of either $2,100 \mathrm{~mm}$ or $3,500 \mathrm{~mm}$. The fiber lay-up, stacking sequence, and mechanical properties of the flanges and web of the HFRP I-beams were presented by the authors elsewhere [Nguyen et al. 2014, 2015]. Two series of specimens with double-lap splice joints were investigated. F-series specimens included the HFRP beams with the splice joints in the flexural span at the mid-span section. They were connected by two HFRP I-sections of two equal half lengths of $L_{1}=L_{2}=$ $1,750 \mathrm{~mm}$ (figure 2a). S-series specimens consist of the HFRP beams with the splice joints in the shear span at the location of $200 \mathrm{~mm}$ apart from the loading point. They were assembled by two HFRP Isections of two different half lengths of $L_{l}=500 \mathrm{~mm}$ and $L_{2}=1,600 \mathrm{~mm}$, respectively (figure $2 \mathrm{~b}$ ).

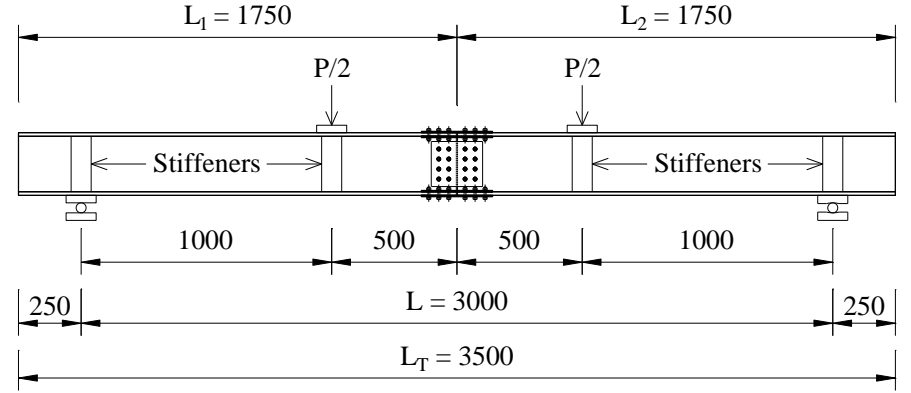

(a)

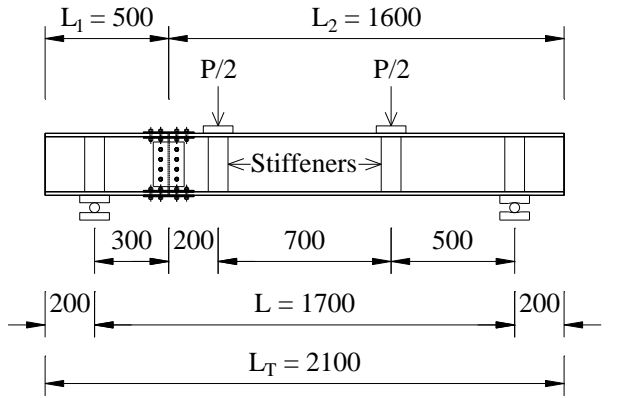

(b)

Figure 2. Details of large-scale joint specimens: (a) side elevation of F-series specimens; and (b) side elevation of $\mathbf{S}$-series specimens (dimensions in $\mathbf{~ m m}$ )

The bonded-and-bolted splice joints were formed at the flanges and web of the HFRP I-beams using either $10 \mathrm{~mm}$ thick FRP splice plates or $9 \mathrm{~mm}$ thick stainless steel splice plates, $10 \mathrm{~mm}$ diameter bolts, and thin-film epoxy layers (figure 3). The FRP plates were designed with a grit-blasted surface finish (figure 4a), while stainless steel plates' inner faces were serrated with $0.5 \mathrm{~mm}$ deep V-notches (figure 4b) to improve bonding strength for the splice joints. Yield stress and tensile strength of the stainless steel splice plates were $245 \mathrm{~N} / \mathrm{mm}^{2}$ and $400 \mathrm{~N} / \mathrm{mm}^{2}$, respectively. The FRP plates were composed of $31 \%$ unidirectional CFRP, $62 \%$ bidirectional GFRP (glass fibers were oriented at $0^{\circ} / 90^{\circ}$ or $\pm 45^{\circ}$ directions), and $7 \%$ E-glass fiber continuous strand mat embedded in a vinylester resin matrix. They had a tensile modulus $E_{11}=45.8 \mathrm{kN} / \mathrm{mm}^{2}$ and a Poisson's ratio $v_{12}=0.285$. Other orthotropic material properties of the FRP plates can be found in [Ishihama 2010]. Three types of bolts were investigated, including stainless steel (SS), high-corrosion resistant steel (HCRS), and FRP. The HCRS bolts had powerful anti-rusting and anti-corrosive properties, resulting from a superior fluorocarbon polymer treatment. Mechanical properties of the SS/HCRS bolts were reported by the authors in [Nguyen et al. 2014]. The FRP bolts were made of E-glass FRP with a tensile modulus of $23.7 \mathrm{kN} / \mathrm{mm}^{2}$, tensile strength of $237 \mathrm{~N} / \mathrm{mm}^{2}$, and shear strength of $111 \mathrm{~N} / \mathrm{mm}^{2}$. 


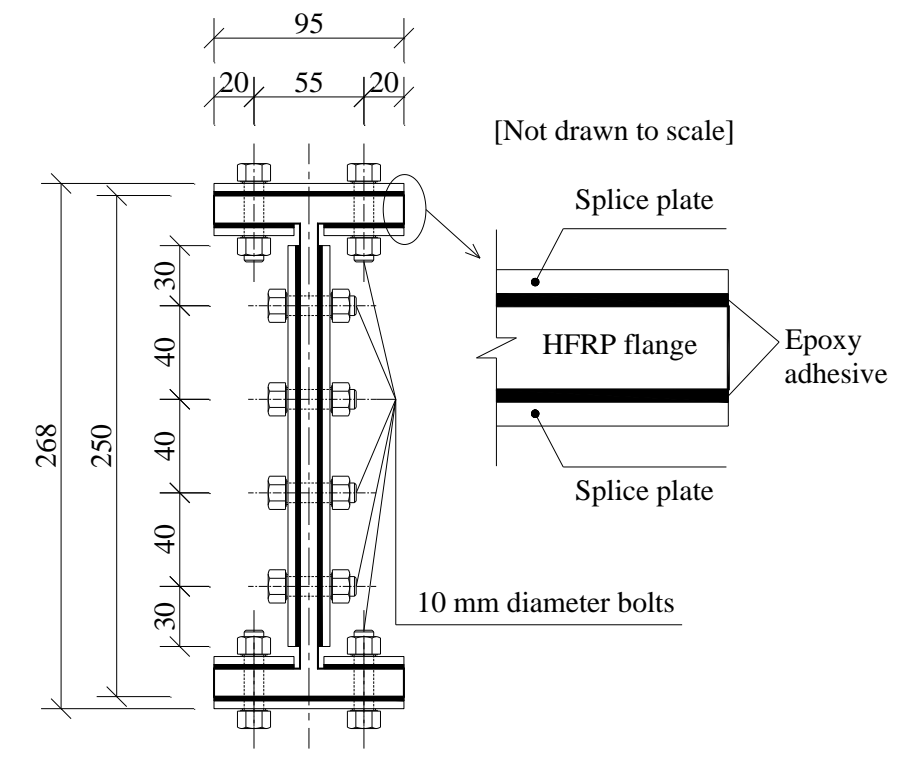

Figure 3. Cross-section of HFRP I-beams with bonded-and-bolted splice joints (dimensions in $\mathbf{m m}$ )

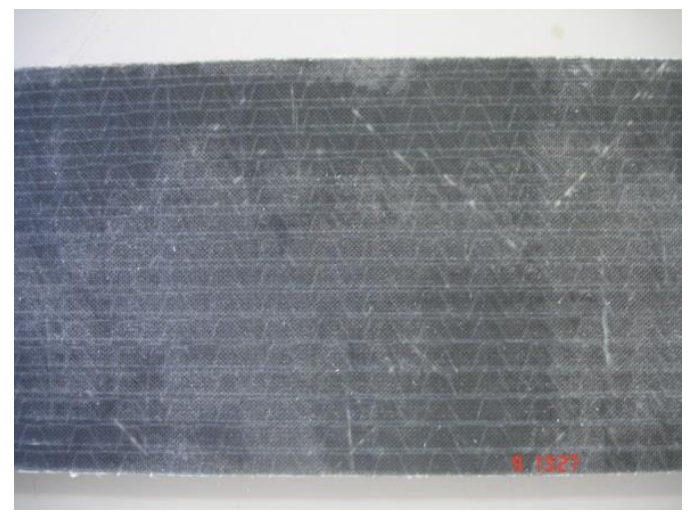

(a)

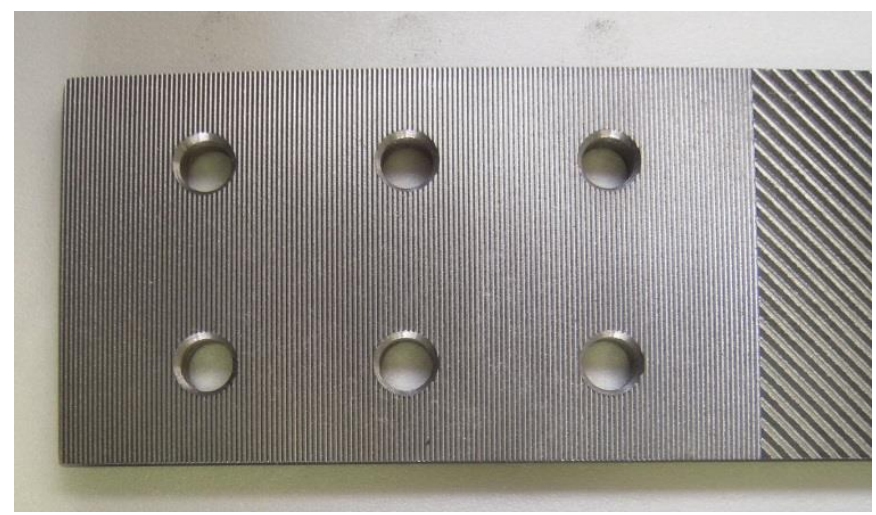

(b)

\section{Figure 4. (a) FRP splice plate with grit-blasted surface finish; and (b) stainless steel V- notched splice plate}

Table 1 shows the flexural beam test variables, which included the two types of the splice plates (i.e. FRP vs. stainless steel), the three types of bolts (i.e. stainless steel, high-corrosion resistant steel, and FRP), and the number of bolts used in the splice joints of the flanges and web of the HFRP I-beams. A label system was used to identify each specimen listed in the first column of Table 1. For all specimens with splice joints, each specimen was designated by two initial letters of the specimen series and the bolt types, followed by a number unique to its type. For the bolt types, it should be noted that the letter "F" denotes FRP bolts, "H" indicates high-corrosion resistant steel (HCRS) bolts, and "S" designates stainless steel (SS) bolts. For example, specimen FF-1 is the joint specimen in the flexural span at the mid-span section using FRP bolts (the first letter " $F$ " indicates the F-series specimen, the second letter "F" denotes the FRP bolts, and the number " 1 " after the hyphen is the numerical order of the joint specimen of the same series using the same types of bolts and splice plates). The two control HFRP I-beams without joints corresponding to F- and S-series specimens are labeled as F-0 and S-0. 
Table 1. Flexural Beam Test Variables

\begin{tabular}{|c|c|c|c|c|c|c|c|c|c|c|c|}
\hline \multicolumn{2}{|c|}{ Specimen } & \multirow[t]{2}{*}{$\begin{array}{c}\text { Joining } \\
\text { span }\end{array}$} & \multicolumn{2}{|c|}{$\begin{array}{l}\text { Length of } \\
\text { joint part }\end{array}$} & \multirow{2}{*}{$\begin{array}{r}\begin{array}{r}\text { Total } \\
\text { length }\end{array} \\
\begin{array}{r}\mathbf{L}_{\mathrm{T}} \\
(\mathrm{mm})\end{array}\end{array}$} & \multirow{2}{*}{$\begin{array}{c}\begin{array}{c}\text { Span } \\
\text { length }\end{array} \\
\begin{array}{c}\mathrm{L} \\
(\mathrm{mm})\end{array} \\
\end{array}$} & \multicolumn{3}{|c|}{ Number of bolts } & \multirow{2}{*}{$\begin{array}{c}\text { Type } \\
\text { of } \\
\text { bolts }\end{array}$} & \multirow{2}{*}{$\begin{array}{l}\text { Type } \\
\text { of } \\
\text { splice } \\
\text { plates }\end{array}$} \\
\hline & & & $\begin{array}{c}\mathbf{L}_{1} \\
(\mathbf{m m})\end{array}$ & $\begin{array}{c}\mathbf{L}_{2} \\
(\mathbf{m m})\end{array}$ & & & $\begin{array}{c}\text { Top } \\
\text { flange }\end{array}$ & $\begin{array}{c}\text { Bottom } \\
\text { flange }\end{array}$ & Web & & \\
\hline \multirow{7}{*}{ 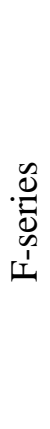 } & F-0 & na & na & na & 3,500 & 3,000 & na & na & na & na & na \\
\hline & FF-1 & Flexural & 1,750 & 1,750 & 3,500 & 3,000 & 8 & 8 & 8 & FRP & FRP \\
\hline & FH-1 & Flexural & 1,750 & 1,750 & 3,500 & 3,000 & 12 & 12 & 16 & $\mathrm{HCRS}^{\mathrm{a}}$ & FRP \\
\hline & FH-2 & Flexural & 1,750 & 1,750 & 3,500 & 3,000 & 8 & 8 & 8 & $\mathrm{HCRS}^{\mathrm{a}}$ & FRP \\
\hline & FH-3 & Flexural & 1,750 & 1,750 & 3,500 & 3,000 & 8 & 4 & 4 & HCRS $^{\mathrm{a}}$ & FRP \\
\hline & FS-1 & Flexural & 1,750 & 1,750 & 3,500 & 3,000 & 12 & 12 & 16 & $\mathrm{SS}^{\mathrm{b}}$ & $\mathrm{SS}^{\mathrm{b}}$ \\
\hline & FS-2 & Flexural & 1,750 & 1,750 & 3,500 & 3,000 & 8 & 8 & 8 & $\mathrm{SS}^{\mathrm{b}}$ & $\mathrm{SS}^{\mathrm{b}}$ \\
\hline \multirow{3}{*}{$\begin{array}{l}\tilde{0} \\
\frac{0}{0} \\
\infty \\
\dot{1}\end{array}$} & S-0 & na & na & na & 2,100 & 1,700 & na & na & na & na & na \\
\hline & SH-1 & Shear & 500 & 1,600 & 2,100 & 1,700 & 8 & 8 & 4 & $\mathrm{HCRS}^{\mathrm{a}}$ & FRP \\
\hline & SS-1 & Shear & 500 & 1,600 & 2,100 & 1,700 & 8 & 8 & 8 & $\mathrm{SS}^{\mathrm{b}}$ & $\mathrm{SS}^{\mathrm{b}}$ \\
\hline
\end{tabular}

${ }^{a}$ High-corrosion resistant steel.

${ }^{b}$ Stainless steel.

Specimen Fabrications. Fabrication of the specimens with the bonded-and-bolted splice joints included: (1) drilling holes in the flanges and web of the HFRP I-beams and in the splice plates with predefined bolt-end distance and longitudinal and transverse spacing. A bolt-end distance of equal to or greater than $3 d$ ( $d=$ nominal diameter of bolt) was used, while the longitudinal and transverse spacing were equal to or greater than $4 d$. The hole diameters were 5 percent larger than the diameters of the bolts to facilitate assembly of the joints. Diamond bits were used to drill the holes in order to avoid an excessive temperature increase of the resin matrix included in the HFRP beams; and (2) thin-film epoxy layers approximately $0.5-1 \mathrm{~mm}$ thick were pasted on the inner faces of the splice plates and the outer faces of the flanges and web of the HFRP I-beams in the joint locations. The splice plates were then connected to the flanges and web of the HFRP I-beams using bolts, washers, and nuts. A preset torque was then applied to all the bolts. A higher torque $(20 \mathrm{~N}-\mathrm{m})$ was used for the SS and HCRS bolts, while a lower torque (10 N-m) was used for the FRP bolts (due to the lower tensile strength of the GFRP bolts as compared to the SS and HCRS bolts). All specimens with bonded-and-bolted splice joints were exposed to a room temperature of $20^{\circ} \mathrm{C}$ and cured for at least 24 hours. A two-component solvent-free epoxy adhesive (Sikadur-30) was used and its mechanical properties were presented by the authors elsewhere [Hai and Mutsuyoshi 2012].

Test Setup and Measurement. All specimens were simply supported and subjected to four-point static flexural loading. F-series specimens (including control beam F-0 and specimens with splice joints in the flexural span at the mid-span section) had a span length of 3,000 $\mathrm{mm}$ and a loading span of 1,000 $\mathrm{mm}$ (figure 2a). S-series specimens (consisting of control beam S-0 and specimens with splice joints in the shear span) had a span length of $1,700 \mathrm{~mm}$ and a loading span of $700 \mathrm{~mm}$ (figure 2b). Wire/laser transducers and linear voltage displacement transducers (LVDT) were used to measure beam deflection at the mid-span section and under the loading points. A number of strain gages were attached in the flexural 
span, shear span, and near the loading points to measure the strain distribution. A high-speed camera was placed in front of the beams to record sudden failure. Hollow GFRP box stiffeners with nominal dimensions of $30 \times 60 \times 220 \mathrm{~mm}$ and a wall thickness of $4 \mathrm{~mm}$ were bonded on both sides of the HFRP Ibeams by epoxy adhesive to prevent web buckling (figure 2 ).

\section{Test Result and Discussion}

\section{F-Series Specimens (with Bonded-and-Bolted Splice Joints in the Flexural Span at the Mid- Span Section)}

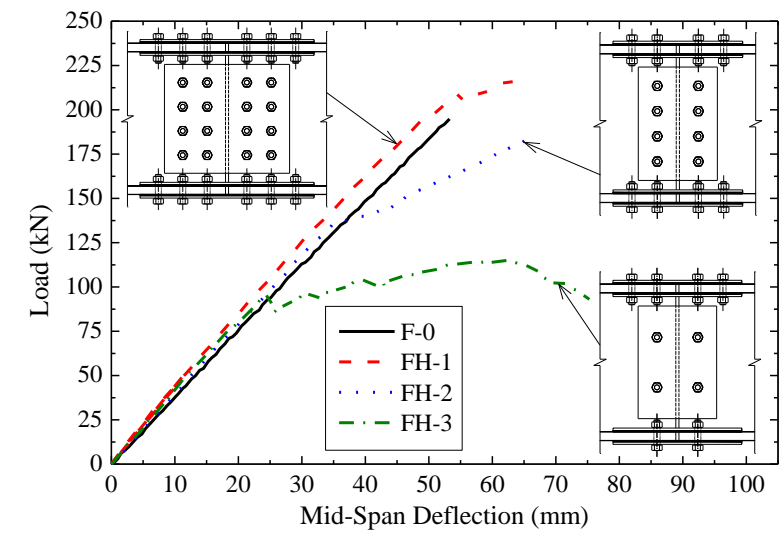

Figure 5. Load versus mid-span curves of F-series specimens

The load versus mid-span deflection curves of the control beam F-0 and the joint specimens FH-1, FH-2, and FH-3 are shown in figure 5. These joint specimens used the HCRS bolts and the FRP splice plates for the splice connections in the flanges and web of the HFRP I-beams. The result indicates that the control beam F-0 behaves almost linearly up to the failure load of $195 \mathrm{kN}$. It failed due to crushing of fibers near the loading point, followed by delamination of the compression flange and web crushing. The stiffness of the joint specimens FH-1, FH-2, and FH-3 is slightly higher than that of the control beam F-0. This may be attributed to the presence of the FRP splice plates and the HCRS bolts in the splice joints. Joint specimen FH-1 (with 12 HCRS bolts in each flange and 16 HCRS bolts in the web) shows the highest strength and stiffness, while the specimen FH-3 (with 8 HCRS bolts in the top flange, 4 HCRS bolts in the bottom flange, and 4 HCRS bolts in the web) exhibits the lowest. It is the fact that the number of HCRS bolts used in the top and bottom flanges of specimen FH-1 are respectively 1.5 and 3 times larger than those of specimen FH-3. In addition, the number of HCRS bolts used in the web of specimen FH-1 are 4 times larger than those of specimen FH-3, resulting in stiffer joints of specimen FH-1. The stiffness and strength of specimen FH-2 (with 8 HCRS bolts in each flange and in the web) are in between those of specimens FH-1 and FH-3. Stiffness reductions of specimens FH-2 and FH-3 were observed at approximately $139 \mathrm{kN}$ and $97 \mathrm{kN}$, corresponding to mid-span deflections of about $36 \mathrm{~mm}$ and $25 \mathrm{~mm}$, respectively. These stiffness reductions may result from the debonding of the bonded-and-bolted splice joints in the tension flange. Both specimens FH-2 and FH-3 failed inside the splice joints. As a result, these specimens did not attain full strength and stiffness as compared to the control beam F- 0 . On the other hand, specimen FH-1, with the largest number of HCRS bolts in the flanges and web, shows slightly higher strength and stiffness in comparison to the control beam F-0. However, the failure of this specimen is brittle due to the crushing of fibers near the loading point, followed by delamination of the compression flange and web crushing (Figure 6). Failure of specimen FH-2 was crushing of fibers inside the splice joints at the compression flange, followed by delamination and web crushing, while specimen FH-3 failed due to debonding of epoxy layers and shearing of HCRS bolts in the tension flange. It should be noted 
from figure 5 that specimens FH-2 and FH-3 shows more ductile behavior than specimen FH-1. It may be thus a good idea to design the HFRP beams to fail in the splice joints to prevent the brittle failure of the beams.
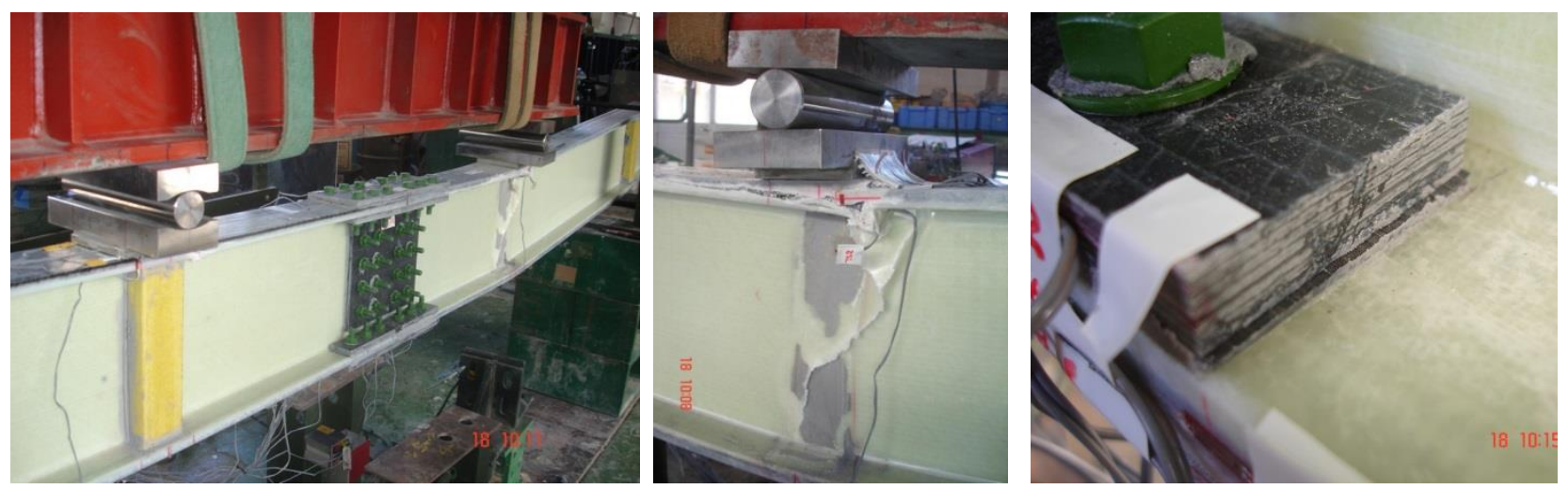

Figure 6. Failure modes of specimen FH-1

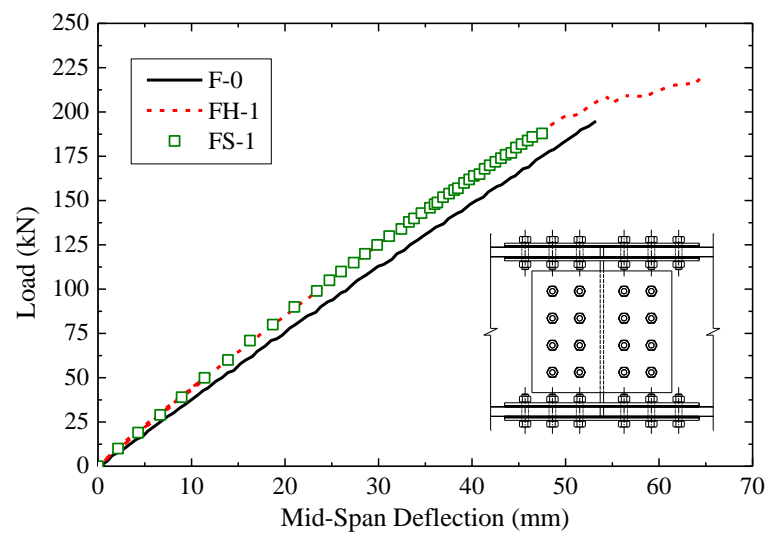

(a)

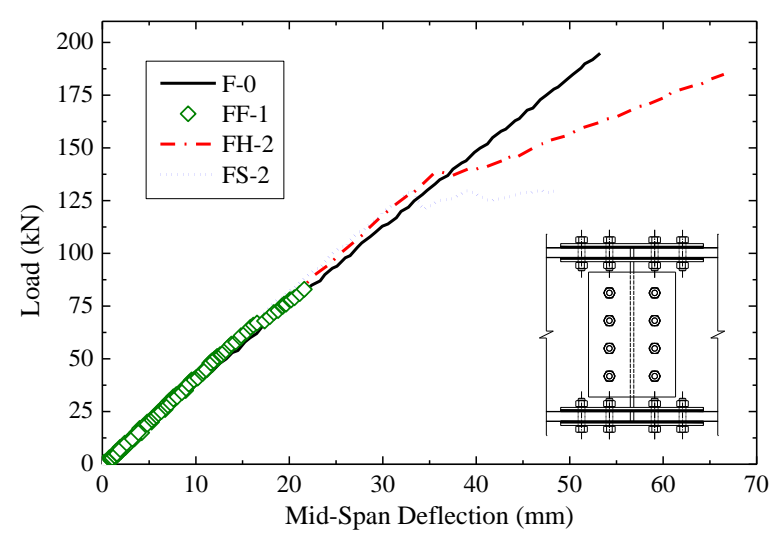

(b)

Figure 7. Effect of bolt types and splice plates on stiffness and strength of $F$-series specimens: (a) specimens with 12 bolts in each flange and 16 bolts in the web; and (b) specimens with 8 bolts in each flange and 8 bolts in the web

Effect of the bolt types and splice plates on stiffness and strength of F-series specimens is shown in figure 7. Joint specimens FH-1 and FS-1 were configured with 12 bolts in each flange and 16 bolts in the web (figure 7a). Specimen FH-1 used FRP splice plates in combination with HCRS bolts, while specimen FS1 was connected by stainless steel V-notched splice plates and SS bolts. Since the diameter and strength of HCRS and SS bolts are almost identical, the major difference between specimens FS- 1 and FH-1 is the splice plates. As can be seen in figure 7a, both specimens FS-1 and FH-1 have the same stiffness, which is slightly higher than that of the control beam F-0. However, the strength of specimen FH-1 is about $17 \%$ higher than that of specimen FS-1. The strength improvement observed in specimen FH-1 may be attributed to the use of the FRP splice plates. The grit-blasted surface finish of the FRP splice plates is found to significantly improve the bonding strength for the bonded-and-bolted splice joints of the HFRP I-beams. Although the V-notched splice plates were reported by the authors to have greater bonding capacity than conventional flat steel splice plates [Hai and Mutsuyoshi 2010, 2012], the FRP splice plates with the grit-blasted surface finish are even better than the V-notched splice plates. These innovative FRP 
splice plates bonded very well with the flanges and web of the HFRP I-beams, and were employed to connect the HFRP I-beams of the first HFRP pedestrian bridge in Japan [Nguyen et al. 2014, 2015]. Both specimens FH-1 and FS-1 had similar failure modes, which were crushing of fibers near the loading point followed by delamination of the compression flange and web crushing (figure 6). However, delamination of the FRP splice plate for the inner flange surface was observed in the tension flange of specimen FH-1. It is worthwhile to note that the delamination/debonding did not happen at the interface between the FRP splice plates and the HFRP bottom flange as observed in figure 6. This result confirms that the gritblasted surface finish of the FRP splice plates can effectively contribute to making a strong bond with the HFRP I-beams.

Figure $7 \mathrm{~b}$ shows the effect of the bolt types and splice plates on the strength and stiffness of the joint specimens FF-1, FH-2, and FS-2. These specimens were configured with 8 bolts in each flange and 8 bolts in the web. Specimens FF-1 and FH-2 used FRP plates for the splice joints, while specimen FS-2 employed stainless steel V-notched splice plates. FRP, HCRS, and SS bolts were used for specimens FF1, FH-2, and FS-2, respectively. As can be seen from figure 7b, the stiffness of specimen FF-1 is comparable to that of the control beam F-0, while the stiffness of specimens FH-2 and FS-2 are slightly higher. This is attributed to the fact that the stiffness of the FRP bolts (used for specimen FF-1) is about 8 times lower than those of the HCRS and SS bolts (used for specimens FH-2 and FS-2, respectively). Specimen FF-1 failed at a relatively low ultimate load of $82.9 \mathrm{kN}$, which is $135 \%$ lower than that of the control beam F-0. The failure mode of this specimen was debonding of the epoxy layers and shearing of the FRP bolts in the tension flange, followed by web rotation. Although both specimens FF-1 and FH-2 used the same type of FRP plates and the same number of bolts for the splice joints, they used different types of bolts. Specimen FH-2 used HCRS bolts, while specimen FF-1 employed FRP bolts. The ultimate load of specimen FH-2 is about $123 \%$ higher than that of specimen FF-1. This is because the tensile strength of the HCRS bolts is approximately 2.2 times larger than that of the FRP bolts. By comparing specimens FH-2 and FS-2, which had identical bolt strength but different splice plates (i.e. FRP versus stainless steel), it was found that the strength of specimen FH-2 is about 1.42 times higher than that of specimen FS-2. This may be attributed to the grit-blasted surface finish of the FRP splice plates used for specimen FH-2, which results in excellent bonding between the FRP plates and the flanges and web of the HFRP I-beams. The failure mode of specimen FH-2 was crushing of fibers in the splice joints of the compression flange, followed by delamination of the compression flange and web crushing. Delamination of the FRP splice plate for the inner flange surface was observed in the tension flange of specimen FH-2. Similar to specimen FH-1, the delamination/debonding did not happen at the interface between the FRP splice plates and the HFRP tension flange. This result verifies that the grit-blasted surface finish of the FRP splice plates is adequate to generate robust bonding for the splice joints of the HFRP I-beams.

S-Series Specimens (with Bonded-and-Bolted Splice Joints in the Shear Span). Load versus mid-span deflection curves of S-series specimens (including the control beam S-0 and two joint specimens, SH-1 and SS-1) are plotted in figure 8. The control beam S-0 shows almost linear behavior up to the load of approximately $303 \mathrm{kN}$. The load was then decreased due to delamination of the HFRP tension flange in the shear span. The failure mode of this beam was delamination of the tension flange and crushing of fibers near the loading point, followed by web crushing.

As can be seen in figure 8, both joint specimens SH-1 and SS-1 were configured with 8 bolts in each flange. For the web, specimen SH-1 used 4 bolts, while specimen SS-1 used 8 bolts. Joint specimen SH-1 with the FRP plates and the HCRS bolts shows the highest ultimate load of about $348 \mathrm{kN}$. This may be attributed to the effect of the grit-blasted surface finish of the FRP splice plates, resulting in good bonding between the FRP plates and the HFRP I-beams. On the other hand, joint specimen SS-1 with the stainless steel (SS) V-notched splice plates and the SS bolts exhibits highest stiffness. This is due to the fact that the stiffness of the steel splice plates used for specimen SS-1 is much higher than that of the FRP splice 
plates used for specimen SH-1. Additionally, the number of bolts used in the web splice of specimen SS-1 is twice that as compared to specimen SH-1.

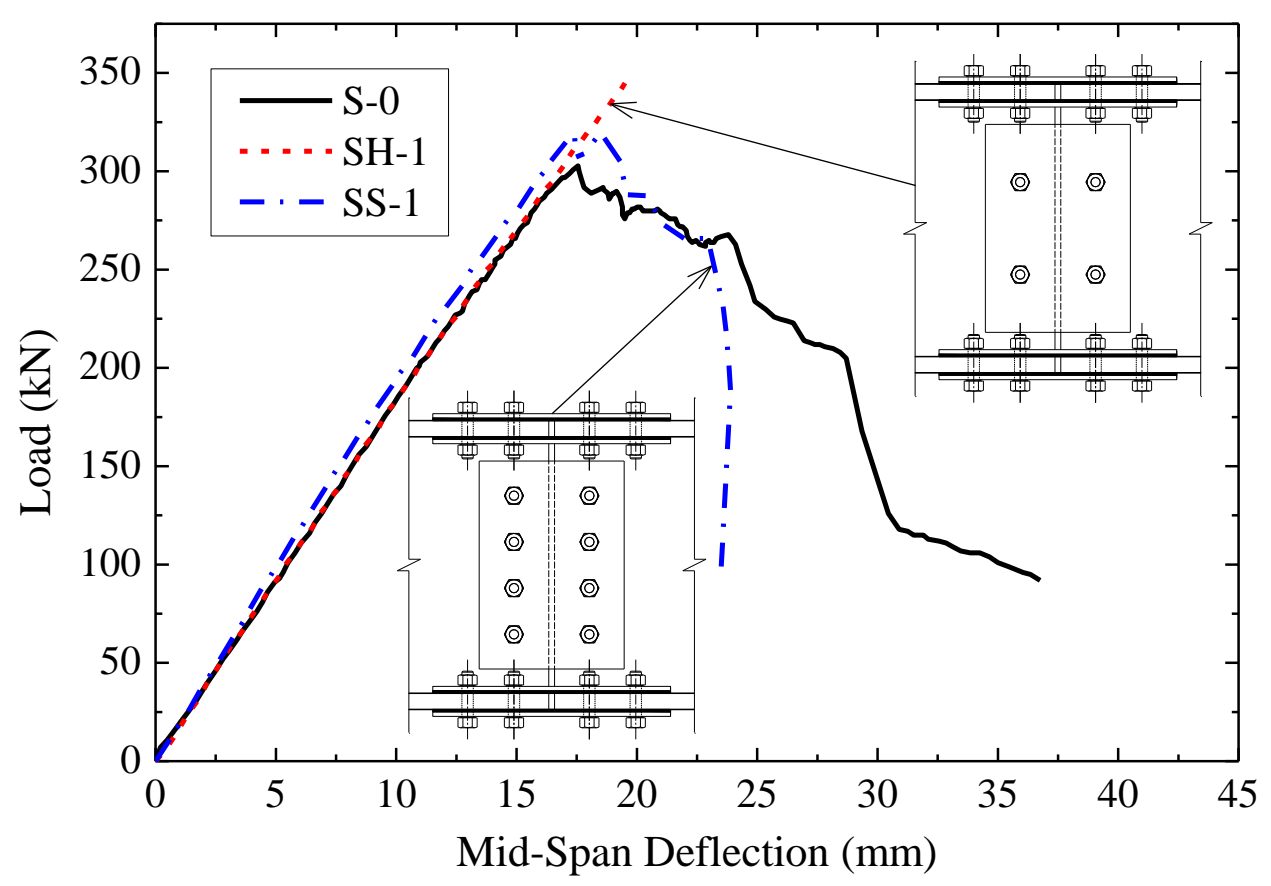

Figure 8. Load versus mid-span curves of S-series specimens

Specimen SS-1 with V-notched splice plates shows a post-failure behavior, similar to the control specimen S-0. This may result from the slippage of the splice joints in the tension flange of specimen SS1. Indeed, by examining the strain readings of the strain gauges attached on the outer surface of the Vnotched splice plate in the bottom flange of specimen SS-1, it was found that there was a debonding between the SS splice plates and the HFRP bottom flange when the load exceeded $239 \mathrm{kN}$. After the debonding, a part of the tension load carried by the epoxy adhesive in the splice joints may be transmitted to the bolts, which may cause the bolts to be bent. These may result in the slippage of the joints. On the other hand, specimen SH-1 showed brittle behavior caused by the sudden fracture of fibers near the loading point. It is evident from the strain readings that major debonding did not happen at the splice joints in the tension flange of specimen SH-1, resulting in relatively small slippage of the joints.

\section{CONCLUSION}

The combined use of high-corrosion resistant steel (HCRS) bolts, epoxy adhesive, and grit-blastedsurface-finish FRP splice plates in double-lap splice joints provides an effective solution for joining the HFRP I-beams. The rough surface of the FRP splice plates and the epoxy bonding contribute to an improvement in the joint stiffness and strength.

Prior to debonding, the stiffness of the bonded-and-bolted splice joints is dependent mainly upon the strength of the epoxy adhesive and the bonding surface of splice plates, while the ultimate load and failure mode of the joints are governed by the number and strength of bolts. The result indicates that the joint specimens with failures in the splice connections show more ductile behavior than those with failures beyond the connections, attributed to the slippage of the splice connections. It may be thus a good idea to design the HFRP beams to fail in the splice connections to prevent brittle failure of the beams. 


\section{ACKNOWLEDGEMENTS}

The authors gratefully acknowledge the financial supports from Japan Ministry of Economy, Trade, and Industry (METI) for this research project. We would like to thank the Fukui Fibertech Co., Ltd. and Toray Industries Inc. for providing the FRP materials. Gratitude is extended to Mr. Kensuke Shiroki and Mr. Tomoya Arai of the Structural Material Laboratory at Saitama University for their assistance in preparing and conducting the experiments. The authors would also appreciate the support provided by the College of Information Technology and Engineering at Marshall University.

\section{REFERENCES}

Camanho, P.P., and F. L. Matthews. Stress Analysis and Strength Prediction of Mechanically Fastened Joints in FRP: A Review. Composites Part A, Vol. 28A, 1997, pp. 529-547.

Hai, N. D., and H. Mutsuyoshi. Behavior of Bolted/Bonded Joints in Pultruded Hybrid CFRP/GFRP Composites. Journal of Structural Engineering, JSCE, Vol. 56, 2010, pp. 23-31.

Hai, N. D., and H. Mutsuyoshi. Structural Behavior of Double-Lap Joints of Steel Splice Plates Bolted/Bonded to Pultruded Hybrid CFRP/GFRP Laminates. Journal of Construction and Building Materials, Vol. 30, 2012, pp. 347-359.

Hai, N. D., H. Mutsuyoshi, S. Asamoto, and T. Matsui. Structural Behavior of Hybrid FRP Composite IBeam. Journal of Construction and Building Materials, Vol. 24, No. 6, 2010, pp. 956-969.

Hart-Smith, L.J. Adhesive Bonding of Composite Structures: Progress to Date and Some Remaining Challenges. Journal of Composites Technology \& Research, Vol. 24, No. 3, 2002, pp. 133-153.

Hart-Smith, L.J. Bonded-Bolted Composite Joints. Journal of Aircraft, Vol. 22, No. 11, 1985, pp. 9931000 .

Ishihama, T. Development of Joint for Hybrid FRP Members. Master thesis, Saitama University, 2010 (in Japanese).

Kelly, G. Quasi-Static Strength and Fatigue Life of Hybrid (Bonded/Bolted) Composite Single-Lap Joints. Composite Structures, Vol. 72, No. 1, 2006, pp. 119-129.

Mutsuyoshi, H., H. Nguyen, W. Zatar, and T. Ishihama. Flexural Behavior of Pultruded Hybrid FiberReinforced Polymer I-Beams with Bonded-and-Bolted Splice Joints. Transportation Research Record: Journal of the Transportation Research Board (in press), Transportation Research Board of the National Academies, Washington, D.C., 2016.

Nelson, W. D., B. L. Bunin, and L. J. Hart-Smith. Critical Joints in Large Composite Aircraft Structure. NASA CR-3710, 1983.

Nguyen, H., H. Mutsuyoshi, and W. Zatar. Flexural Behavior of Hybrid Composite Beams. In Transportation Research Record: Journal of the Transportation Research Board, No. 2332, Transportation Research Board of the National Academies, Washington, D.C., 2013, pp. 53-63.

Nguyen, H., H. Mutsuyoshi, and W. Zatar. Hybrid FRP-UHPFRC Composite Girders: Part 1 Experimental and Numerical Approach. Composite Structures, Vol. 125, 2015, pp. 631-652.

Nguyen, H., H. Mutsuyoshi, and W. Zatar. Push-Out Tests for Shear Connections between UHPFRC Slabs and FRP Girder. Composite Structures, Vol. 118, 2014, pp. 528-547.

Nguyen, H., W. Zatar, and H. Mutsuyoshi. Hybrid Fiber-Reinforced Polymer Girders Topped with Segmental Precast Concrete Slabs for Accelerated Bridge Construction. In Transportation Research 
Record: Journal of the Transportation Research Board, No. 2407, Transportation Research Board of the National Academies, Washington, D.C., 2014, pp. 83-93.

Nguyen, H., W. Zatar, and H. Mutsuyoshi. Hybrid FRP-UHPFRC Composite Girders: Part 2 - Analytical Approach. Composite Structures, Vol. 125, 2015, pp. 653-671.

Turvey, G.J., and C. Xavier. Flexural Behaviour of Pultruded Glass Fibre Reinforced Polymer Composite Beams with Bolted Splice Joints. Composite Structures, Vol. 119, 2015, pp. 543-550. 